\title{
POTENCIAL DE PROPAGAÇÃo DE CULTIVARES DE MARMELEIRO POR ESTAQUiA ${ }^{1}$
}

\author{
RAFAEL PIO², JOÃO PAULO CAMPOS DE ARAÚJO ${ }^{3}$, JOÃO ALEXIO SCARPARE FILHO ${ }^{4}$, FRANCISCO DE ASSIS \\ ALVES MOURÃO FILHO ${ }^{4}$, ÂNGELO ALBÉRICO ALVARENGA ${ }^{5}$, ENILSON ABRAHÃO ${ }^{6}$
}

\begin{abstract}
RESUMO - Devido à escassez de trabalhos com o enraizamento de estacas de marmeleiro, realizou-se o presente trabalho com o objetivo de verificar o potencial de enraizamento de estacas de cultivares de marmeleiro. Utilizaram-se estacas lenhosas e lisas coletadas de plantas de marmeleiro 'Radiolo', 'Mendoza Inta-37', 'Much Prolife', 'Pineapple', 'Smyrna', 'De Patras', 'Provencia', 'Van Deman', 'Provance', 'Meliforme', 'Portugal' (Cydonia oblonga) e 'Japonês' (Chaenomelis sinensis L.), sendo estas padronizadas com $20 \mathrm{~cm}$ de comprimento. As estacas foram enterradas até a metade do comprimento em canteiro de terra e coberto por tela sombrite 50\%, sendo umedecidas diariamente através de regas manuais. Após 75 dias, coletaram-se os seguintes dados biométricos: porcentagem de estacas enraizadas e brotadas, número de folhas e brotos, comprimento da maior raiz, comprimento médio das brotações e número de raízes emitidas por estaca. As cultivares Pineapple, De Patras, Provencia e Mendoza Inta-37 apresentaram maior potencialidade de propagação via estaquia.
\end{abstract}

Termos para indexação: Cydonia oblonga; Chaenomelis sinensis L.; marmelo; produção de mudas.

\section{POTENCIAL OF PROPAGATION OF CULTIVARS OF QUINCE FOR CUTTINGS}

\begin{abstract}
Due to the shortage of works with the quince cutting, the present work was developed with the objective to verify the rooting potential of quince cultivars cutting. Hardwoody cuttings of quince were collected from 'Radiolo', 'Mendoza Inta-37', 'Much Prolife', 'Pineapple', 'Smyrna', 'De Patras', 'Provencia', 'Van Deman', 'Provance', 'Meliforme', 'Portugal' (Cydonia oblonga) and 'Japonês' (Chaenomelis sinensis L.), being these samples standardized with $20 \mathrm{~cm}$ of length. Soon after, half of the length of the cutting was put in a substrate constituted by soil and covered by sombrite $50 \%$, being daily humidified by water. After 75 days, were evaluated the percentage of rooting and sprouting, number of leaves and sprouts, length of the largest root and sprouting and number of roots emitted by cutting. The cultivars Pineapple, De Patras, Provencia and Mendoza Inta-37 presented larger potentiality of propagation of cutting.
\end{abstract}

Index terms: Cydonia oblonga; Chaenomelis sinensis L.; quince; seedlings production.

\section{INTRODUÇÃO}

A cultura do marmeleiro está concentrada principalmente no Sul do Estado de Minas Gerais, nos municípios de Delfim Moreira, Cristina, Maria da Fé, Virgínia e Marmelópolis, onde a marmelocultura, na década de 30, exerceu importante papel no desenvolvimento socioeconômico da região, com a implantação de indústrias processadoras de marmelos para a fabricação de doces e compotas (Hiroto, 2002). O Estado de Minas Gerais, embora ainda seja o maior produtor de marmelos do País, apresenta sérias limitações ao cultivo, destacando-se a falta de incentivos, problemas fitossanitários e desinteresse do mercado consumidor (Abrahão et al., 1996). No Estado de São Paulo, marmeleiro, com somente 1.140 plantas cultivadas em 4,3 ha, tem como principal cultivar a Portugal, sendo os principais municípios produtores de marmelos Tietê e Vargem Grande do Sul. Mesmo com as diversas pesquisas desenvolvidas, a cultura do marmeleiro não avançou no Estado de São Paulo (Barbosa et al., 2003), isso provavelmente devido a problemas fitossanitários (Campo Dall'orto et al., 1986), entre outros.

Apesar de os frutos de marmeleiros da espécie Cydonia oblonga possuírem sementes viáveis, estas são em pequena quantidade (menos de 10), produzindo pela reprodução sexual plântulas desuniformes, o que não é desejado no estabelecimento de plantios comerciais (Pasqual et al., 2001). Sendo assim, a estaquia ou enxertia vem a ser a alternativa de propagação mais viável para os marmeleiros, mantendo assim as características genéticas das plantas-matrizes, uniformidade, porte reduzido e precocidade de produção (Hartmann \& Kester, 1990; Fachinello et al., 1995; Meletti, 2000).

O uso do marmeleiro 'Japonês' (Chaenomeles sinensis L.) via seminífera, como porta-enxerto para as outras espécies e cultivares de marmelos, tem se mostrado viável, principalmente pelo elevado número de sementes por fruto (aproximadamente 150), poder germinativo, uniformidade e afinidade (Abrahão et al., 1991).

Na propagação do marmeleiro via estaquia, são utilizadas estacas com 30-40 cm de comprimento retiradas de plantas no final do período de repouso hibernal, aproveitando o material oriundo da poda de inverno (Ranzolin, 1948; Murayama, 1973). Essas estacas são colocadas diretamente na cova de plantio, deixando-se apenas duas gemas acima do nível do solo (Souza \& Drummond-Gonçalves, 1954). O insucesso desta técnica de propagação pode ser comparado ao da figueira, que, devido à não-coincidência do plantio das estacas com o período chuvoso na região Sudeste, tem propiciado baixo índice de enraizamento. Neste caso, utilizam-se duas estacas por cova, ocorrendo, mesmo assim, baixo enraizamento, acarretando um plantio desuniforme e a necessidade de replantios (Gonçalves, 2002).

Uma alternativa na propagação do marmeleiro seria o enraizamento das estacas previamente em ambiente controlado, podendo utilizar estacas de menor diâmetro e comprimento. Essa prática facilita o manejo no viveiro, a seleção de plantas de qualidade e o plantio no período chuvoso através de mudas em torrão, possibilitando a obtenção de um pomar uniforme e vigoroso (Pio, 2002).

Devido à escassez de estudos que envolvem a propagação do marmeleiro, realizou-se o presente trabalho com o intuito de verificar a capacidade de enraizamento de estacas de diferentes espécies e cultivares de marmeleiros.

\section{MATERIALEMÉTODOS}

O presente trabalho foi desenvolvido na Escola Superior de Agricultura "Luiz de Queiroz", da Universidade de São Paulo (USP/ ESALQ), Piracicaba-SP, no período de agosto a outubro de 2003.

\footnotetext{
${ }^{1}$ (Trabalho 054/2004). Recebido: 07/05/2004. Aceito para publicação: 21/07/2004.

${ }^{2}$ Eng $^{\circ}$. Agrônomo, M.Sc., Doutorando do curso de Fitotecnia, Depto. de Produção Vegetal - USP/ESALQ. Av. Pádua Dias, nº 11, CEP 13418-900, Piracicaba-SP. Autor para correspondência: rafapio@esalq.usp.br.

${ }^{3}$ Eng $^{\circ}$. Agrônomo, Mestrando do curso de Fitotecnia, Depto. de Produção Vegetal, Universidade de São Paulo, Escola Superior de Agricultura “Luiz de Queiroz" USP/ESALQ. Av. Pádua Dias, nº 11, CEP 13418-900, Piracicaba-SP.jp.campos@uol.com.br.

${ }^{4}$ Eng ${ }^{\circ}$. Agrônomo, Dr., Prof. de Fruticultura do Depto. de Produção Vegetal - USP/ESALQ. Av. Pádua Dias, nº 11, CEP 13418-900, Piracicaba-SP. jascarpa@ esalq.usp.br famourao@esalq.usp.br.

${ }^{5}$ Eng $^{\circ}$. Agrônomo, Dr., Pesquisador EPAMIG-CTSM, C.P. 176, CEP 37200-000, Lavras-MG. angelo@epamig.ufla.br.

${ }^{6}$ Eng $^{\circ}$. Agrônomo, M.Sc., Pesquisador EMBRAPA/EPAMIG-CTSM, C.P. 176, CEP 37200-000, Lavras-MG. enilson@epamig.ufla.br.
} 
TABELA 1 - Análise de variância da porcentagem de estacas enraizadas (PEE), número de raízes emitidas por estaca (NREE), comprimento da maior raiz $(\mathrm{CMR}, \mathrm{cm})$, porcentagem de estacas brotadas (PEB), número de folhas (NF) número de brotos (NB) e comprimento médio das brotações (CMB, cm) de cultivares de marmeleiros. USP/ESALQ, Piracicaba-SP, 2003.

\begin{tabular}{lcccccccc}
\hline \multicolumn{1}{c}{ Causas da variação } & GL & PEE & NREE & CMR & PEB & NF & NB & CMB \\
\cline { 2 - 9 } & \multicolumn{1}{c}{ Cultivares } & 11 & $9,23^{*}$ & $9,58^{*}$ & $5,24^{*}$ & $9,94^{*}$ & $2,06^{*}$ & $1,82^{\text {ns }}$ \\
\hline Resíduo & 36 & - & - & - & - & - & $4,27^{*}$ \\
cv (\%) & - & 15,07 & 17,38 & 24,26 & 16,51 & 20,58 & 29,53 & 25,53 \\
DMS & - & 6,00 & 1,07 & 2,04 & 6,80 & 3,84 & 0,30 & 3,61 \\
\hline
\end{tabular}

ns: não significativo.

*: significativo $(P<0,05)$

Coletaram-se estacas lenhosas e lisas de plantas de marmeleiro 'Radiolo', 'Mendoza Inta-37', 'Much Prolife', 'Pineapple', 'Smyrna', 'De Patras', 'Provencia', 'Van Deman', 'Provance', 'Meliforme', 'Portugal' (Cydonia oblonga) e 'Japonês' (Chaenomelis sinensis L.). As estacas foram padronizadas com $20 \mathrm{~cm}$ de comprimento, efetuando-se um corte reto acima de uma gema no ápice e em bisel, na base da estaca, abaixo de uma gema. Em seguida, enterrou-se metade do comprimento das estacas em canteiro constituído por terra, coberto por sombrite $50 \%$ e umedecidas diariamente através de regas manuais.

O delineamento utilizado foi o inteiramente casualizado, totalizando 12 tratamentos (cultivares de marmeleiros), com 4 repetições e unidade experimental formada por 10 estacas.

Após 75 dias, coletaram-se os seguintes dados biométricos: porcentagem de estacas enraizadas e brotadas, número de folhas e brotos, comprimento da maior raiz, comprimento médio das brotações e número de raízes emitidas por estaca.

Os dados foram submetidos à análise de variância e as médias ao teste Scott-Knott, ao nível de 5\% de probabilidade (Gomes, 2000). As análises foram realizadas pelo programa computacional Sistema para Análise de Variância - SISVAR (Ferreira, 2000).

\section{RESULTADOS E DISCUSSÃO}

Através da análise de variância, constatou-se que houve diferença significativa para todas as variáveis em estudo, à exceção para o número de brotos (Tabela 1 ).

As cultivares 'De Patras' e 'Pineapple' apresentaram maior enraizamento (62,5\% e 52,5\%, respectivamente); as cultivares 'Provencia' e 'Mendoza Inta-37' apresentaram 45,0\% e 35,0\%, respectivamente, e as demais cultivares, os menores índices de enraizamento, as quais não diferiram entre si (Tabela 2).

TABELA 2 - Porcentagem de estacas enraizadas (PEE), número de raízes emitidas por estaca (NREE) e comprimento da maior raiz (CMR, $\mathrm{cm})$ de cultivares de marmeleiros. USP/ESALQ, Piracicaba-SP, 2003.

\begin{tabular}{|c|c|c|c|c|c|}
\hline \multirow[t]{2}{*}{ Cultivares } & \multicolumn{5}{|c|}{ Variável Analisada* } \\
\hline & PEE & NREE & & CMR & \\
\hline Radiolo & $15,0 \mathrm{c}$ & 9,15 & $\mathrm{~b}$ & 11,50 & $\mathrm{a}$ \\
\hline Mendoza Inta-37 & $35,0 \mathrm{~b}$ & 2,86 & $\mathrm{c}$ & 6,74 & $\mathrm{~b}$ \\
\hline Much Prolife & $20,0 \mathrm{c}$ & 2,37 & $\mathrm{c}$ & 1,41 & $\mathrm{~b}$ \\
\hline Pineapple & 52,5 a & 7,00 & $\mathrm{~b}$ & 13,23 & $\mathrm{a}$ \\
\hline Smyrna & $7,5 \mathrm{c}$ & 1,50 & c & 1,00 & $\mathrm{~b}$ \\
\hline De Patras & 62,5 a & 4,86 & $\mathrm{c}$ & 11,01 & $\mathrm{a}$ \\
\hline Provencia & $45,0 \mathrm{~b}$ & 5,42 & $\mathrm{c}$ & 10,71 & $\mathrm{a}$ \\
\hline Van Deman & $10,0 \mathrm{c}$ & 1,87 & $\mathrm{c}$ & 5,00 & $\mathrm{~b}$ \\
\hline Provance & $25,0 \mathrm{c}$ & 2,69 & $\mathrm{c}$ & 5,00 & $\mathrm{~b}$ \\
\hline Meliforme & $10,0 \mathrm{c}$ & 2,50 & $\mathrm{c}$ & 7,87 & $\mathrm{a}$ \\
\hline Portugal & $25,0 \mathrm{c}$ & 12,12 & $\mathrm{a}$ & 14,57 & $\mathrm{a}$ \\
\hline Japonês & $12,5 \mathrm{c}$ & 2,25 & $\mathrm{c}$ & 2,32 & $\mathrm{~b}$ \\
\hline cv $(\%)$ & 15,07 & 17,38 & & 24,26 & \\
\hline
\end{tabular}

* Médias seguidas da mesma letra na coluna não diferem significamente entre si, pelo teste Scott-Knott, ao nível de 5\% de probabilidade.
Rufato et al. (2001), trabalhando com o enraizamento de estacas de marmeleiros 'Portugal', 'Pineapple', 'Mendoza Inta-37' e 'Meliforme', com $12 \mathrm{~cm}$ de comprimento, obtiveram apenas $5 \%$ de enraizamento para a cultivar Portugal, não ocorrendo enraizamento das demais cultivares. Essa diferença pode estar correlacionada com a época de estaquia, uma vez que o referido trabalho foi realizado em abril, fora da época da poda hibernal, conseqüentemente, possuindo o material propagativo menor quantidade de reservas, substâncias fundamentais ao enraizamento (Fachinello et al., 1995).

A cultivar Portugal apresentou maior número de raízes emitidas por estaca (12,12); já as cultivares Radiolo e Pineapple apresentaram 9,15 e 7 raízes, em média, respectivamente (Tabela 2). As cultivares Portugal $(14,57 \mathrm{~cm})$, Pineapple $(13,23 \mathrm{~cm})$, Radiolo (11,5 cm), De Patras (11,01 cm), Provencia $(10,71 \mathrm{~cm})$ e Meliforme $(7,87 \mathrm{~cm})$ apresentaram resultados superiores, em comparação às demais cultivares para o comprimento da maior raiz.

A formação de raízes adventícias em estacas pode ser direta e indiretamente controlada por genes (Haissig \& Reimenschneider, 1988). Segundo estes autores, os aspectos genéticos que influenciam no processo de enraizamento de estacas não têm sido investigados. A potencialidade de uma estaca em formar raízes é variável com a espécie e cultivar, podendo ser feita uma classificação entre espécies ou cultivares de fácil, médio ou difícil capacidade de enraizamento, ainda que a facilidade de enraizamento seja resultante da interação de diversos fatores e não apenas do potencial genético (Fachinello et al., 1995).

Para a porcentagem de estacas brotadas, as cultivares Portugal (70\%), De Patras (67,5\%), Pineapple (57,5\%), Mendoza Inta-37 (50\%) e Provencia $(47,5 \%)$ apresentaram resultados superiores, em comparação às demais (Tabela 3). Pio et al. (2002) também verificaram que o marmeleiro 'Portugal' apresenta alta porcentagem de brotação de suas estacas (73,5\%). Rufato et al. (2001), trabalhando com o enraizamento de estacas de marmeleiros 'Portugal', 'Pineapple', 'Mendoza Inta-37' e 'Meliforme',

TABELA 3 - Porcentagem de estacas brotadas (PEB), número de folhas (NF) número de brotos (NB) e comprimento médio das brotações $(\mathrm{CMB}, \mathrm{cm})$ de cultivares de marmeleiros. USP/ ESALQ, Piracicaba-SP, 2003.

\begin{tabular}{llccc}
\hline Cultivares & \multicolumn{4}{c}{ Variável Analisada* } \\
\cline { 2 - 5 } & PEB & NF & CMB \\
\hline Radiolo & $17,5 \mathrm{c}$ & $23,42 \mathrm{a}$ & $19,50 \mathrm{a}$ \\
Mendoza Inta-37 & $50,0 \mathrm{a}$ & $11,67 \mathrm{~b}$ & $15,41 \mathrm{a}$ \\
Much Prolife & $32,5 \mathrm{~b}$ & $5,95 \mathrm{~b}$ & $2,03 \mathrm{~b}$ \\
Pineapple & $57,5 \mathrm{a}$ & $19,84 \mathrm{a}$ & $25,42 \mathrm{a}$ \\
Smyrna & $12,5 \mathrm{c}$ & $11,12 \mathrm{~b}$ & $11,37 \mathrm{~b}$ \\
De Patras & $67,5 \mathrm{a}$ & $10,59 \mathrm{~b}$ & $15,20 \mathrm{a}$ \\
Provencia & $47,5 \mathrm{a}$ & $17,78 \mathrm{a}$ & $15,68 \mathrm{a}$ \\
Van Deman & $12,5 \mathrm{c}$ & $7,00 \mathrm{~b}$ & $4,50 \mathrm{~b}$ \\
Provance & $32,5 \mathrm{~b}$ & $16,62 \mathrm{a}$ & $10,30 \mathrm{~b}$ \\
Meliforme & $10,0 \mathrm{c}$ & $12,00 \mathrm{~b}$ & $8,12 \mathrm{~b}$ \\
Portugal & $70,0 \mathrm{a}$ & $8,00 \mathrm{~b}$ & $2,92 \mathrm{~b}$ \\
Japonês & $37,5 \mathrm{~b}$ & $8,25 \mathrm{~b}$ & $2,07 \mathrm{~b}$ \\
\hline cv (\%) & 16,51 & 20,58 & 25,53 \\
\hline
\end{tabular}

* Médias seguidas da mesma letra na coluna não diferem significamente entre si, pelo teste Scott-Knott, ao nível de 5\% de probabilidade. 
dotados de $12 \mathrm{~cm}$ de comprimento, obtiveram cerca de $10 \%$ de brotação. Essa controvérsia pode estar ligada ao menor tamanho das estacas que, conseqüentemente, possuem menor quantidade de gemas.

Para o número de folhas, as cultivares Radiolo $(23,42)$, Pineapple $(19,84)$, Provencia $(17,78)$ e Provance $(16,62)$ se destacaram entre as demais, que não diferiram estatisticamente entre si (Tabela 3). No referente ao comprimento médio das brotações, verifica-se que as cultivares Pineapple (25,42 cm), Radiolo (19,5 cm), Provencia (15,68 cm), Mendoza Inta-37 $(15,41 \mathrm{~cm})$ e De Patras $(15,2 \mathrm{~cm})$ apresentaram melhores resultados.

Pio et al. (2002), trabalhando com o enraizamento de estacas dos marmeleiros 'Portugal' e 'Japonês' tratadas com ácido indolbutírico (AIB), verificaram que a concentração de $2.000 \mathrm{mg} . \mathrm{L}^{-1}$ promoveu maior porcentagem de enraizamento para o 'Portugal' $(45,36 \%)$ e a concentração de 1.000 mg.L. - $^{-1}$ para o 'Japonês' (13,4\%). Visioli et al. (2003), em outro trabalho desenvolvido com os referidos marmeleiros, observaram um acréscimo de enraizamento efetuando a estratificação das estacas em areia, por 45 dias, e posterior tratamento com AIB para o marmeleiro 'Portugal', onde obtiveram melhores resultados com a concentração de $4.000 \mathrm{mg} . \mathrm{L}^{-1}(69,7 \%)$. No presente trabalho, obteve-se apenas $25 \%$ de enraizamento para o 'Portugal' e 12,5\% para o 'Japonês', sem a utilização de quaisquer tratamentos nas estacas. Talvez o emprego de técnicas auxiliares ao enraizamento de estacas das cultivares de marmeleiro possa trazer melhores resultados.

\section{CONCLUSÕES}

As cultivares de marmeleiro Pineapple, De Patras, Provencia e Mendoza Inta-37 apresentaram maior potencialidade de propagação via estaquia.

\section{REFERÊNCIASBIBLIOGRÁFICAS}

ABRAHÃO, E.; ALVARENGA, A. A.; SOUZA, M. de. Marmeleiro (Chaenomeles sinensis) cv. Japonês - Porta-enxerto para marmeleiros, pereiras e nespereiras. Revista Brasileira de Fruticultura, Cruz das Almas, v.13, n.2, p.181-182, out. 1991.

ABRAHÃO, E.; SOUZA, M. de; ALVARENGA, A. A. A cultura do marmeleiro em Minas Gerais. Belo Horizonte: EPAMIG, 1996. 23p. (EPAMIG - Boletim Técnico, 47).

BARBOSA, W.; POMMER. C. V.; RIBEIRO, M. D.; VEIGA, R. F. de A.; COSTA, A. A. Distribuição geográfica e diversidade varietal de frutíferas e nozes de clima temperado no Estado de São Paulo. Revista Brasileira de Fruticultura, Jaboticabal, v.25, n.2, p.341-344, ago. 2003.

CAMPO DALL'ORTO, F. A.; OJIMA, M.; BARBOSA, W.; SABINO, J. C.; VEIGA, A. A.; RIGITANO, O. Cultivo de marmeleiros em alta densidade de plantio. In: CONGRESSO BRASILEIRO DE FRUTICULTURA, 8., 1986, Salvador. Anais... Salvador: SBF, 1986. v.2, p.409-415.

FACHINELLO, J. C.; HOFFMANN, A.; NACHTIGAL, J. C.; KERSTEN, E.; FORTES, G. R. de L. Propagação de plantas frutíferas de clima temperado. 2. ed. Pelotas: UFPel, 1995. 178p.
FERREIRA, D. F. Análise estatística por meio do SISVAR (Sistema para Análise de Variância) para Windows versão 4.0. In: REUNIÃO ANUAL DA REGIÃO BRASILEIRA DA SOCIEDADE INTERNACIONAL DE BIOMETRIA, 45., 2000, São Carlos. Anais... São Carlos: UFSCar, 2000. p.255-258.

GOMES, F. P. Curso de estatística experimental. 14. ed. Piracicaba: USP/ ESALQ, 2000. 477p.

GONÇALVES, F. C. Formas de acondicionamento a frio de estacas e mudas de figueira (Ficus carica L.). 2002. 84p. Dissertação (Mestrado em Agronomia) - Universidade Federal de Lavras, Lavras, 2002.

HAISSIG, B. E.; REIMENSCHNEIDER, E. D. Genetic effects on adventitious rooting. In: DAVIS, T. D.; HAISSIG, B. E.; SANKLHA, N. (Ed.). Adventitious root formation in cuttings. Portland: Discorides Press, 1988. p.47-60.

HARTMANN, H. T.; KESTER, D. E. Propagacion de plantas: principios y practicas. México: Compañia Editorial Continental, 1990. 760p.

HIROTO, C. H. Enraizamento de estacas dos marmeleiros 'Japonês' e 'Portugal' em diferentes substratos e concentrações de ácido indolbutírico. 2002. 56f. Dissertação (Mestrado em Agronomia), Universidade Federal de Lavras, Lavras, 2002.

MELETTI, L. M. M. Propagação de frutíferas tropicais. Guaíba: Agropecuária, 2000. 239p.

MURAYAMA, S. Fruticultura. 2. ed. Campinas: Instituto Campineiro de Ensino Agrícola, 1973. 428p.

PASQUAL, M.; CHALFUN, N. N. J.; RAMOS, J. D.; VALE, M. R. do; SILVA, C. R. de. R. e Fruticultura comercial: propagação de plantas frutíferas. Lavras: UFLA/FAEPE, 2001. 137p.

PIO, R. Ácido indolbutírico e sacarose no enraizamento de estacas apicais e desenvolvimento inicial da figueira (Ficus carica L.). 2002. 109f. Dissertação (Mestrado em Agronomia) - Universidade Federal de Lavras, Lavras, 2002.

PIO, R.; GONTIJO, T.C.A.; CARRIJO, E.P.; TOMASETTO, F.; VISIOLI, E.L.; CHALFUN, N.N.J.; RAMOS, J.D. Enraizamento de estacas lenhosas de marmeleiro 'Portugal' e 'Japonês' tratadas com ácido indolbutírico. In: CONGRESSO DA PÓS-GRADUAÇÃODA UFLA, 11., 2002, Lavras. Anais... Lavras: UFLA, 2002. CD-ROM.

RANZOLIN, F. Breves instruções sobre a cultura do marmeleiro. Porto Alegre: Secretaria de Estado dos Negócios da Agricultura, Indústria e Comércio, 1948. 8p. (Circular Técnica, 69).

RUFATO, L.; MEYER, G. de A.; BIANCHI, V. J.; FACHINELLO, J. C. Enraizamento de estacas lenhosas de cultivares de marmeleiro (Cydonia oblonga) tratadas com floroglucinol. Revista Brasileira de Fruticultura, Jaboticabal, v.23, n.3, p.742-744, dez. 2001.

SOUZA, J. S. I. de; DRUMMOND-GONÇALVES, R. Cultura, doenças e pragas do marmeleiro. São Paulo: Chácaras e Quintais, 1954. 56p.

VISIOLI, E. L.; GONTIJO, T. C. A.; CARRIJO, E. P.; TOMASETTO, F.; PIO, R.; RAMOS, J. D.; CHALFUN, N. N. J. Enraizamento de estacas lenhosas de marmeleiros 'Portugal' e 'Japonês' estratificadas em areia e posteriormente imersas em AIB. In: CONGRESSO DE INICIAÇÃO CIENTÍFICA DA UFLA-CICESAL, 16., 2003, Lavras. Anais... Lavras: UFLA, 2003. p.40. 